\title{
The Application of RFID Technology in a Port
}

\author{
R. Khemmar \\ Lecturer \\ Research Institute for \\ Embedded Systems \\ (IRSEEM), ESIGELEC, \\ 76801 Saint Etienne du \\ Rouvray Cedex \\ Rouen, FRANCE
}

\author{
F. Bouzbouz \\ Lecturer \\ IRSEEM, ESIGELEC, \\ 76801 Saint Etienne du \\ Rouvray Cedex \\ Rouen, FRANCE
}

\author{
N. Ragot and X. Savatier \\ Lecturers \\ IRSEEM, ESIGELEC, \\ 76801 Saint Etienne du \\ Rouvray Cedex \\ Rouen, FRANCE
}

\begin{abstract}
The collaborative Project "RORO MAX" has as objective the development of the Roll-On Roll-Off (RORO) activity of the Grand Port Maritime du Havre (GPMH) [4]. This development through a significant increase in RORO traffic and therefore more intelligent management of this flow. In this context, we have developed a RFID solution-based traceability to better manage the large number of vehicles in import and export, and allow the different RORO terminal actors to use an efficient and robust tool. This paper presents two low-cost developed solutions. A measurement and testing in Indoor and Outdoor environment was conducted to validate the proposed solutions.
\end{abstract}

\section{Keywords}

Vehicle tracking, RFID, passive tag, reading distance, radiation diagram, radiated immunity.

\section{INTRODUCTION}

For several years, car flow through the GPMH port is in decline. This worrying situation exacerbated by the severe crisis in the automotive sector (2007-2008) led the GPMH to undertake a general reflection on the industry and strong action to increase the capacity and competitiveness of its treatment RORO terminal [4]. Thus, with the support and the support of partners (institutional, academic and business), the GPMH initiated in 2010 "RORO MAX" collaborative project which aims to combine the skills and expertise of partners to address several issues : creating the conditions for sustainable development of RORO terminal GPMH, The Havre position, the RORO terminal as reference terminal in terms of services for new cars in Europe at the entrance of the "Axis Seine" and doubling the RORO traffic to bring it to 500,000 vehicles/year in 2015. In this context, the Institute for Research in Embedded Electronic Systems (IRSEEM) is a partner of RORO MAX project under the "Traceability WorkPackage" for the development and deployment of RFID [3] traceability solution-based on the ferry terminal [5][7][13][14].

This article focuses on experiments and measurements upstream of choice and/or deployment of traceability solutions to the ferry terminal, presented in the feasibility study. The first section contains in synthesis the feasibility study by recalling the criteria for comparing different solutions, making a focus on the two solutions selected for phase "experimenting and measures". The second section describes the experiments conducted and test environments. The third section presents the results obtained during the indoor and outdoor tests. This section provides a comparison between the two solutions. Finally, this paper will end with a conclusion (forth section) with recommendations on the choice of solutions.

\section{FEASIBILITY STUDY}

\subsection{Keywords Recall}

This scenario provides tracking using passive systems based on market solutions "off the shelf ". It is therefore affixed to vehicles of passive RFID (frequency: $868 \mathrm{MHz}$ standard GS1) tags and deploy terminal gates placed at key locations (i.e. input/output terminal, loading/unloading of the ship, storage area and service area) for reading tags. It also provides a management system for the avoidance of discrimination of all tags in a given area. This scenario uses low-cost systems. The cost of a passive tag is less than $0.50 € /$ piece on volume of more than 100,000 pieces. The cost of infrastructure equipment (cranes, readers, antennas and more communication devices) is required to predict. The order of magnitude for a checkpoint amounted to 7,500 €. To finalize the selection of the hardware solution to deploy a list of criteria has been established taking into account the specific constraints of the port environment: Operating Frequency, Distance reading material dimensions in space, Type of tag, Management the collision, Interfacing to the Information System, Liaison with bar codes and deployment on the ferry terminal.

\subsection{Solutions used for Testing and Measurements}

\subsubsection{Solution 1}

Solution 1 offers RFID traceability system [8] based on RFU63x player [12]. He is a player combining highperformance hardware and intelligent software to solve the most demanding tasks for automatic identification of industrial problems. The microwave RFU63x is specifically dedicated to industrial environments RFID solution [3][6][9]. The device is compact and the antenna is incorporated.

\subsubsection{Solution 2}

The solution consists of two compact readers MRU kind. This is EPC C1G2 UHF RFID readers compatible. Conform to the standard ETSI EN 302 208, MRU drives can be used with UHF passive or semi- passive tags. Their solid architecture allows for easy integration into an existing environment. MRU drives are specifically designed for Automated Vehicle Identification (AVI). They are particularly suitable for applications where parking management passive technology and long range are required. MRU readers have a sealed box that houses all the functional parts of the reading unit: antenna, radio frequency source, receiver, processor and communications interfaces. MRU readers have multiple communication interfaces to facilitate integration (TTL, Ethernet, USB, etc.). In addition, the player has an I/O addressing for external devices (control barrier for example). 


\section{MEASUREMENT CAMPAIGNS}

In the development of the technical solution for traceability, a measurement campaign was carried out to characterize the features of a share and validate their use in the context RORO port on the other. Initially, measurements were conducted in a controlled environment (indoor), semi-anechoic chamber. These measurements were used to characterize the radiation pattern and immunity to RF interference sources (radiated immunity). In a second step, measurements were performed outside (outdoor), in conditions close to those obtainable on the terminal conditions.

\subsection{Measurement in a Controlled Environment}

\subsubsection{Objectives Measures}

\subsubsection{Radiation Pattern}

The radiation pattern or a pickup device is the graphic representation of the spatial distribution of the energy radiated by a radio antenna or the power recovered by an energy sensor. In theory, the radiation pattern is established for all points in space at an infinite distance from the antenna. In practice, it is enough to place in the far field at a distance $d_{m}$ depending on the size of the antenna source $\left(d_{s}\right)$ and receiver $d_{r}$ and wavelength $(\lambda)$ of the signal for which the Measurement is made (equation 1) [15].

$$
d_{m}>2 \frac{\left(d_{s}+d_{r}\right)^{2}}{\lambda}
$$

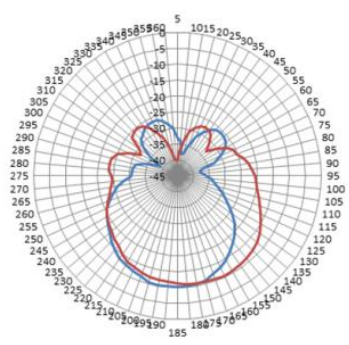

Fig 1: Example of Radiation Pattern (blue: horizontal pattern, red: vertical pattern).

\subsubsection{Test in Radiated Immunity}

The immunity test, also called susceptibility, aims to validate the behavior of a device in response to attacks from external disturbances. These disturbances from other electronic devices or intentional transmitters which produce, by their design and mode of operation, disruptive electromagnetic fields. It is therefore necessary to validate the operation or malfunction of the equipment under test when subjected to these attacks. In this test, the equipment under test is placed (and its wiring) on a ground plane and illuminated via a transmitting antenna [1]. This antenna is connected to a power amplifier, itself supplied by a radio frequency signal generator. Since an electromagnetic field is emitted toward the device under test. The entire required frequency spectrum is then swept in frequency with the field strength and the required modulation.

This test is performed in an anechoic chamber (coated absorbers on the walls simulating space) or reverberation chamber modes (CRBM, Faraday cage equipped with a brewer rotating part changing the volume of the cage is seen as a cavity, thus altering the way the field is set in the cavity).

\subsubsection{Materials used (semi-anechoic chamber)}

The semi-anechoic chamber (see Figure 2) is an electromagnetic metal structure (Faraday cage) covered (partially) absorbers [2]. The metal cavity allows protection against radio radiation outside the electronic devices. Absorbent reduce the reflectivity of the walls and avoid the multiple paths and resonances. This means experimentation allows to behavior approach in free space, while avoiding external radio interference and climatic conditions.

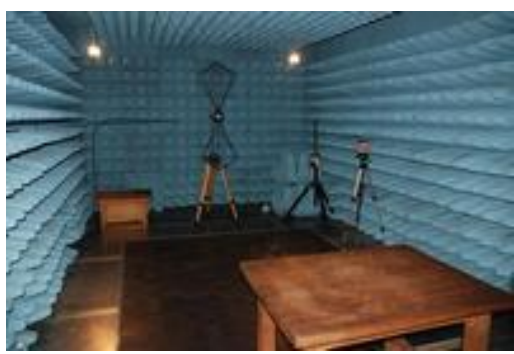

Fig 2: IRSEEM Semi-anechoic room.

\subsubsection{Solution 1: Controlled Indoor Environment} 3.1.3.1 Antenna Diagram

The figure 3 shows the Test Scheme.

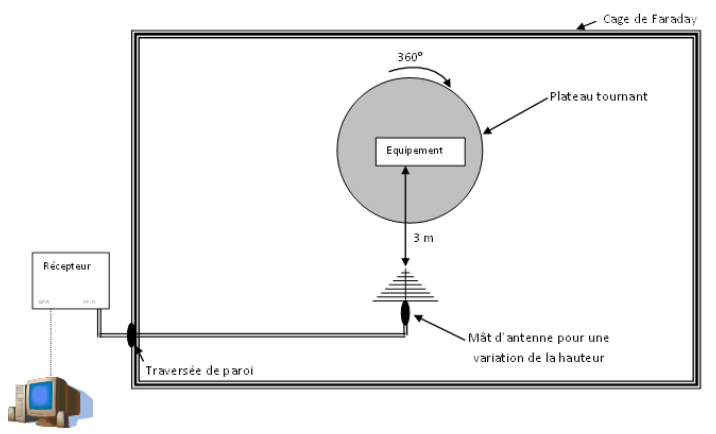

Fig 3: Test Scheme.

\section{Measuring Protocol}

The RFID system is located in the center of the turntable at a fixed height of $1.7 \mathrm{~m}$. The measuring antenna will be placed at two different distances $(2.5 \mathrm{~m}$ and $3 \mathrm{~m})$ and 4 different heights $(1,1.7,3$ and $4 \mathrm{~m})$, all in two polarizations: horizontal and vertical.

\section{Frequency Band}

The figure 4 shows the different configurations of antenna.

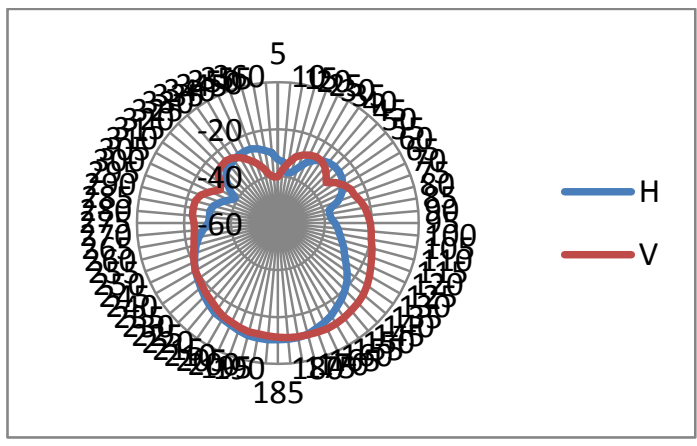

Fig 4.a: Height $1 \mathrm{~m}$ distance $2.5 \mathrm{~m}$. 


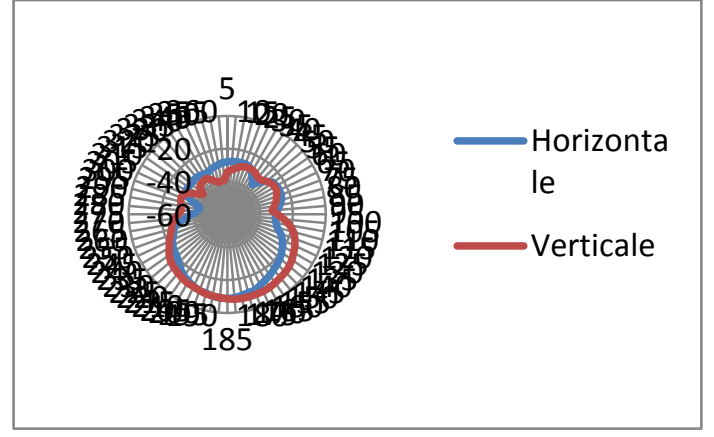

Fig 4.b: Height $1.7 \mathrm{~m}$ distance $2.5 \mathrm{~m}$.

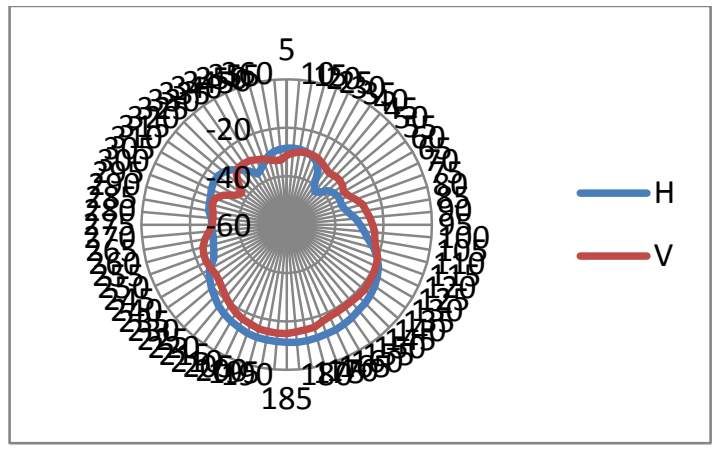

Fig 4.c: Height 3m distance $2.5 \mathrm{~m}$.

\subsubsection{Radiated immunity}

The figure 5 shows the test scheme.

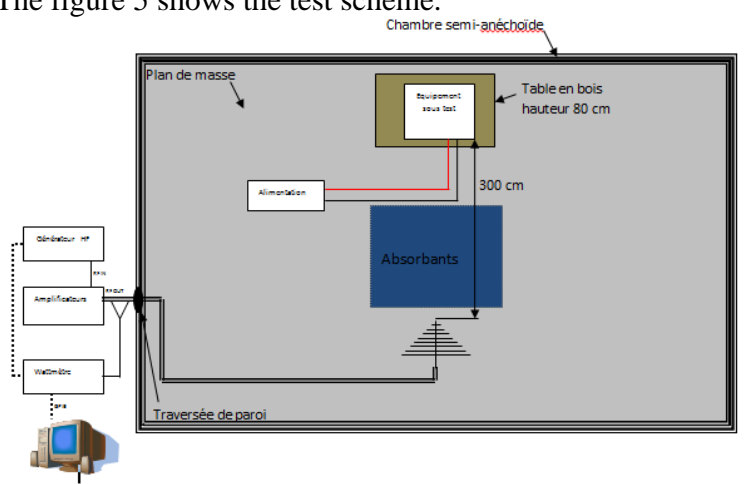

Fig 5: Test Scheme.

The figure 6 shows the Indoor environment tests.
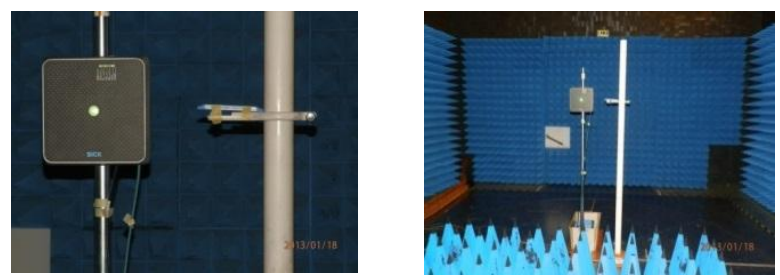

TAG to the side

TAG to the side

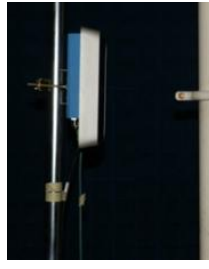

TAG in front
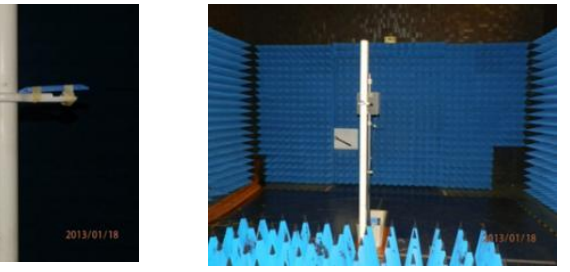

TAG in front
Fig 6: Indoor Environment Tests.

Test 1

Frequency Band

The table 1 presents the frequency bands [11].

Table. 1. Frequency Bands.

\begin{tabular}{|l|l|l|l|}
\hline Min Frequency & Max Frequency & Step & Modulation \\
\hline $80.00 \mathrm{MHz}$ & $1000.00 \mathrm{MHz}$ & $1.0 \mathrm{Pc}$ & $\begin{array}{l}\text { AM } 1000 \mathrm{~Hz} 80 \\
\%\end{array}$ \\
\hline $1400.00 \mathrm{MHz}$ & $2000.00 \mathrm{MHz}$ & $1.0 \mathrm{Pc}$ & $\begin{array}{l}\text { AM } 1000 \mathrm{~Hz} 80 \\
\%\end{array}$ \\
\hline $2000.00 \mathrm{MHz}$ & $2700.00 \mathrm{MHz}$ & $1.0 \mathrm{Pc}$ & $\begin{array}{l}\text { AM } 1000 \mathrm{~Hz} 80 \\
\%\end{array}$ \\
\hline
\end{tabular}

\section{Horizontal Polarization}

The Figures 7.a and 7.b shows the field and the power results.

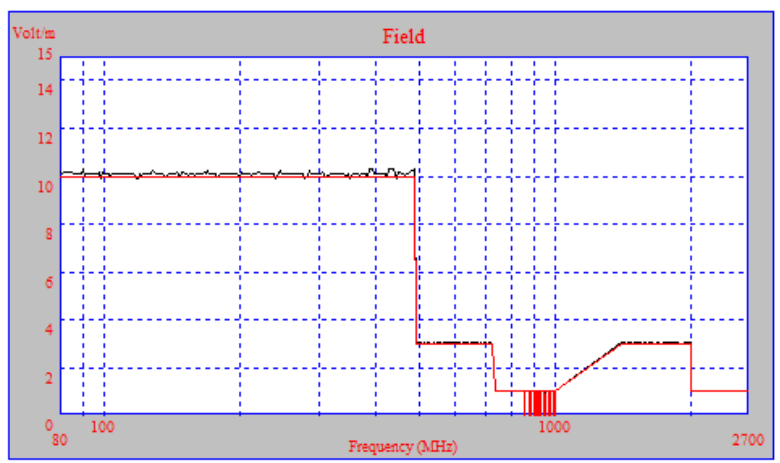

Fig 7.a: Field.

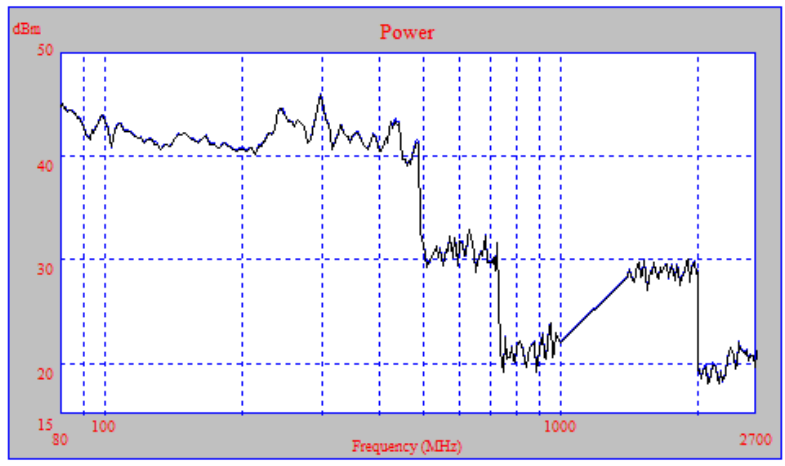

Fig 7.b: Power.

\section{Vertical Polarization}

The figures 8.a and 8.b shows the field and the power results. 


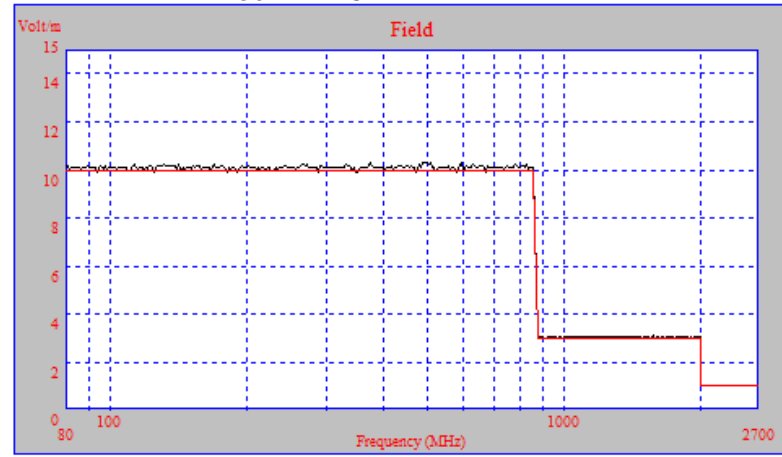

Fig 8.a: Field.

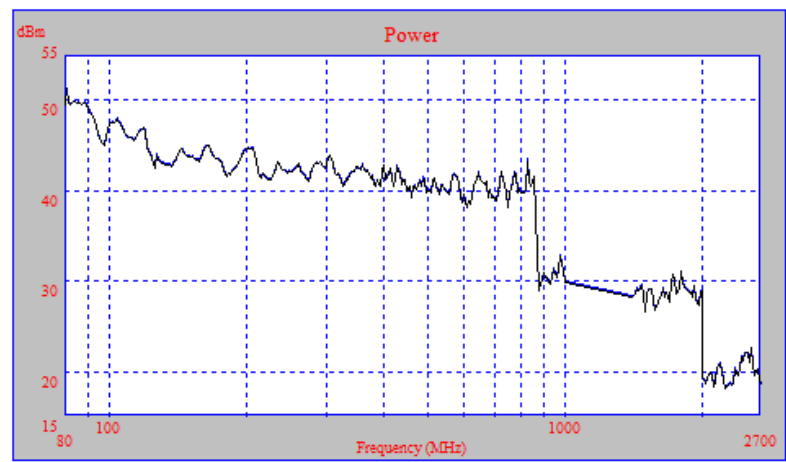

Fig 8.b: Power.

\section{Conclusion}

Many detection losses are recognized between $854 \mathrm{MHz}$ and $1000 \mathrm{MHz}$ for less than $1 \mathrm{~V} / \mathrm{m}$ in horizontal polarization levels $[10,11]$.

\section{Test 2: tag facing the reader}

\section{Horizontal Polarization}

The Figures 9.a and 9.b shows the field and the power results.

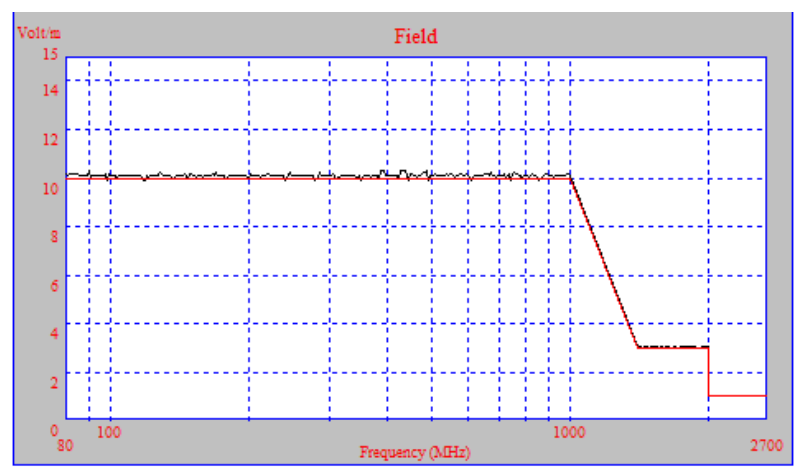

Fig 9.a: Filed.

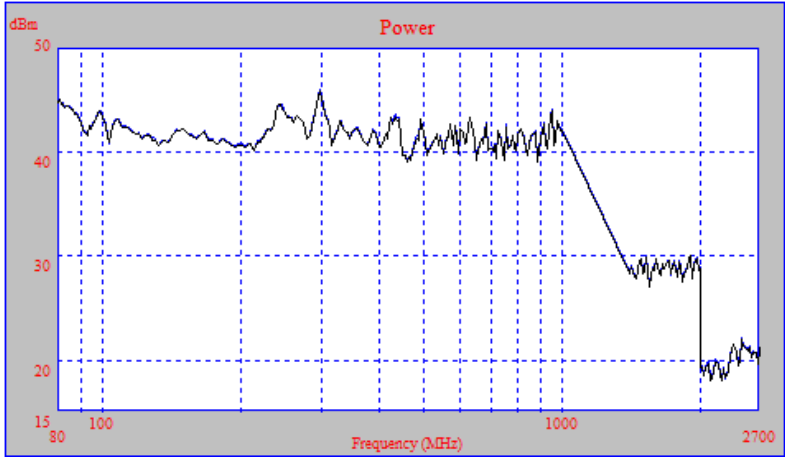

Fig 9.b: Power.

\section{Vertical Polarization}

The figures 10.a and 10.b shows the field and the power results.

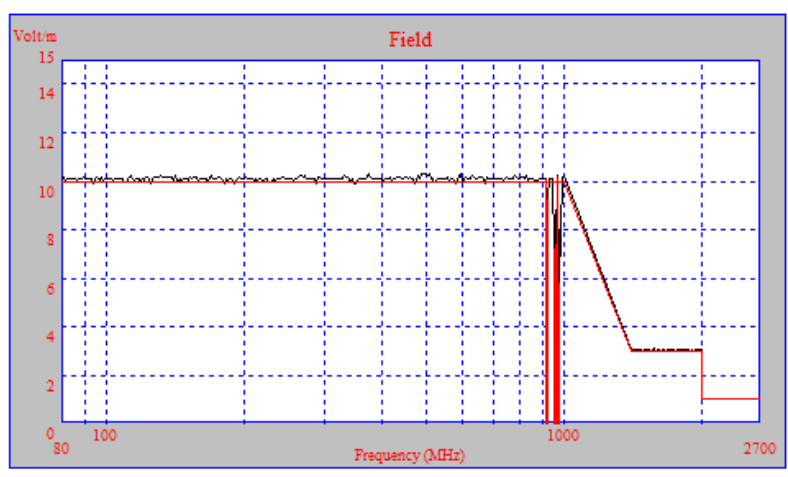

Fig 10.a: Filed.

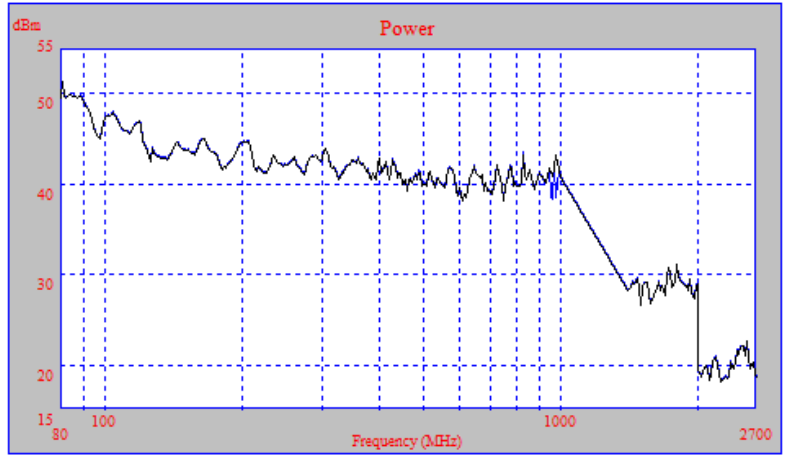

Fig 10.b: Power.

\section{Conclusion}

We have much less damage detection with optimized position of TAG but we find some sensitivity between 915 and $981 \mathrm{MHz}$ for levels between 5.8 and $10.1 \mathrm{~V} / \mathrm{m}$.

3.1.4 Solution 2

\subsubsection{Antenna Diagram}

The figure 11 shows the Test Scheme. 


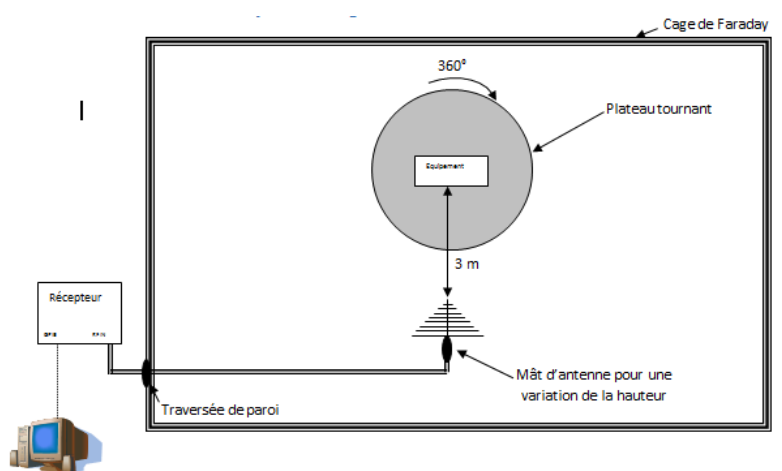

Fig 11: Test Scheme.

\section{Measuring Protocol}

The RFID system is located in the center of the turntable at a fixed height of $1.7 \mathrm{~m}$. The measuring antenna will be placed at two different distances $(2.5 \mathrm{~m}$ and $3 \mathrm{~m})$ and 4 different heights (1, 1.7, 3 and $4 \mathrm{~m})$, all in two polarizations: horizontal and vertical.

\section{Frequency: 868.65 MHz}

The Figures 12 shows the Antenna configuration.

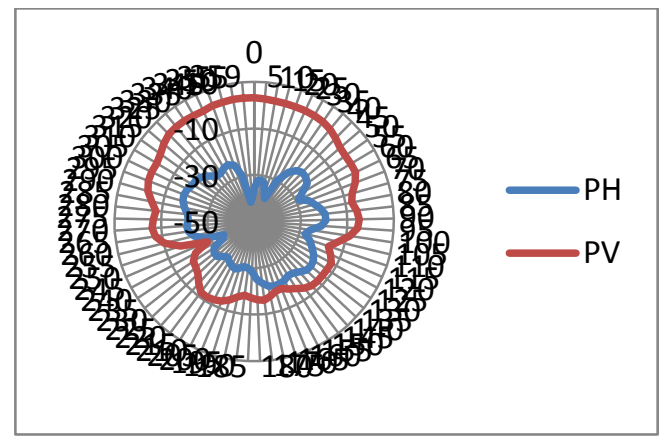

Fig 12.a: Hauteur $1 \mathrm{~m}$ and distance $2.5 \mathrm{~m}$.

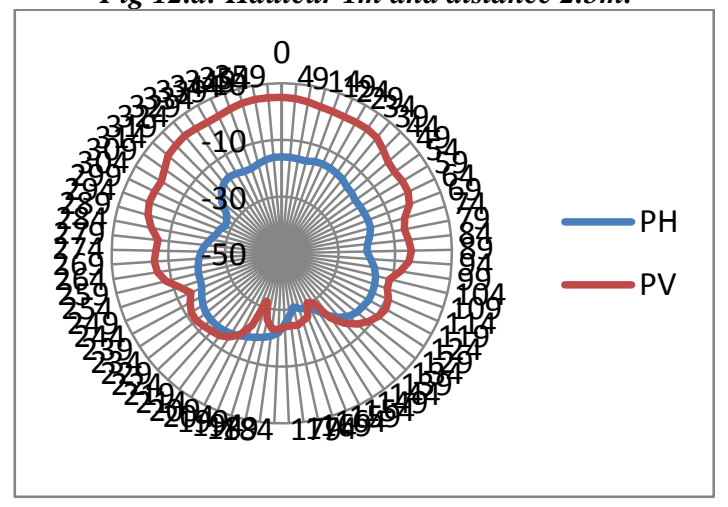

Fig 12.b: Hauteur 1.7m and distance 2.5m.

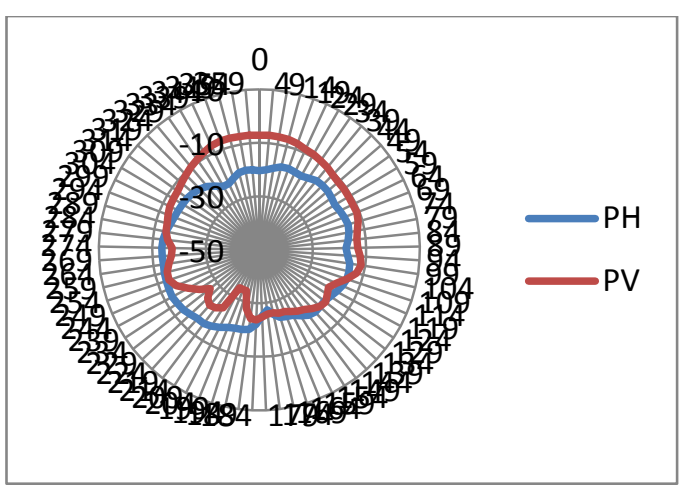

Fig 12.c: Hauteur 4m and distance 2.5m.

\subsubsection{Radiated Immunity}

The figure 13 shows the Test Scheme.

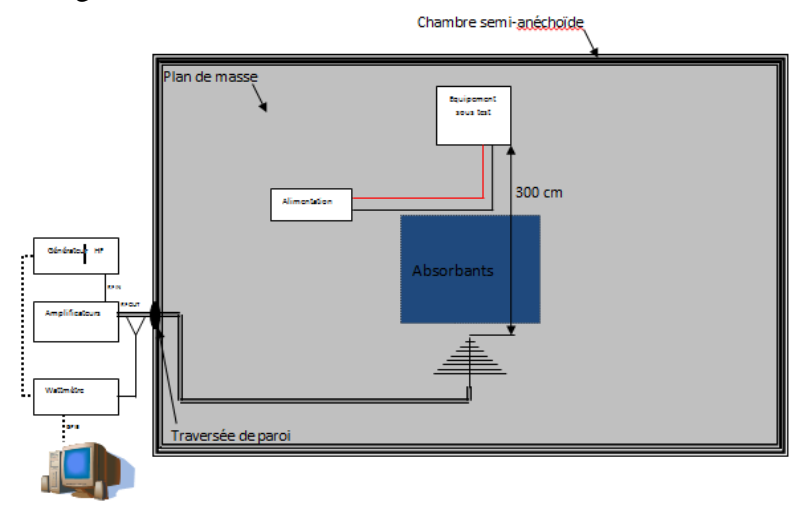

Fig 13: Test Scheme.

We have placed an analog/optical acquisition module on the system output that sends the state of the TAG detection at its output. We have a reference voltage centered around $8 \mathrm{~V}$ when the detection is confirmed. Once the system do not detects the TAG, the voltage drops. The figure 14 shows the Indoor environment testing.
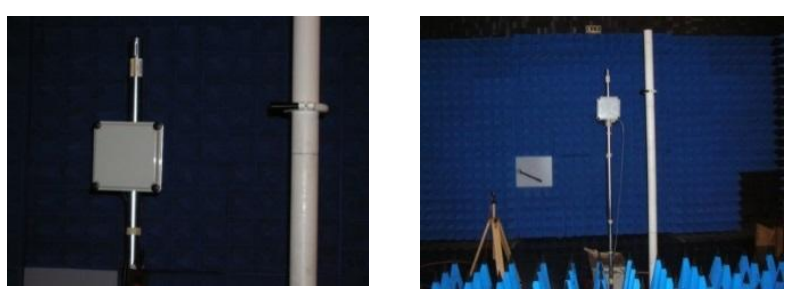

TAG to the side

TAG to the side
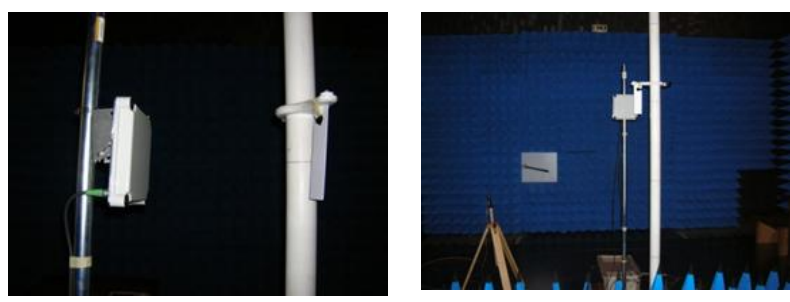

TAG in front

Fig 14: Indoor Environment Tests. 
Test 1

Table 2. Frequency Bands

\begin{tabular}{|l|l|l|l|}
\hline $\begin{array}{l}\text { Min } \\
\text { Frequency }\end{array}$ & $\begin{array}{l}\text { Max } \\
\text { Frequency }\end{array}$ & Step & Modulation \\
\hline $80.00 \mathrm{MHz}$ & $1000.00 \mathrm{MHz}$ & $1.0 \mathrm{Pc}$ & $\begin{array}{l}\text { AM 1000Hz 80 } \\
\%\end{array}$ \\
\hline $1400.00 \mathrm{MHz}$ & $2000.00 \mathrm{MHz}$ & $1.0 \mathrm{Pc}$ & $\begin{array}{l}\text { AM } 1000 \mathrm{~Hz} 80 \\
\%\end{array}$ \\
\hline $2000.00 \mathrm{MHz}$ & $2700.00 \mathrm{MHz}$ & $1.0 \mathrm{Pc}$ & $\begin{array}{l}\text { AM } 1000 \mathrm{~Hz} 80 \\
\%\end{array}$ \\
\hline
\end{tabular}

\section{Horizontal Polarization}

The Figures 15.a and 15.b shows the field and the power results.

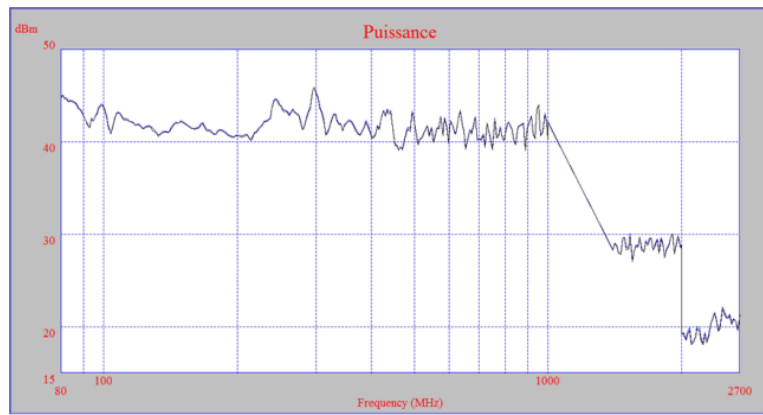

Fig 15.a: Field.

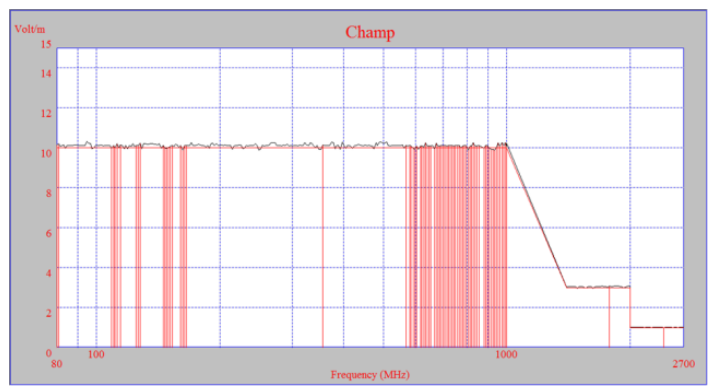

Fig 15.b: Power.

\section{Vertical Polarization}

The Figures 16.a and 16.b shows the field and the power results.

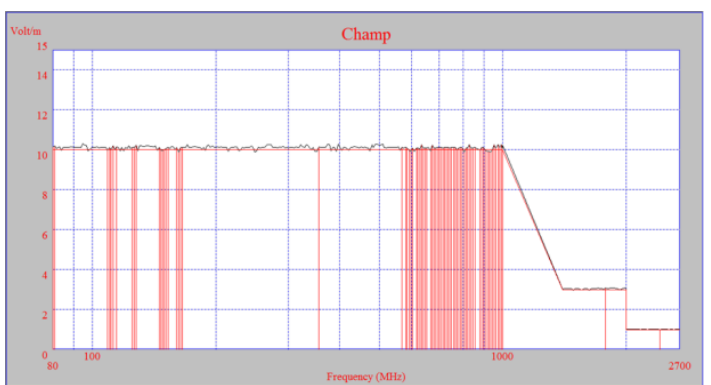

Fig 16.a: Field.

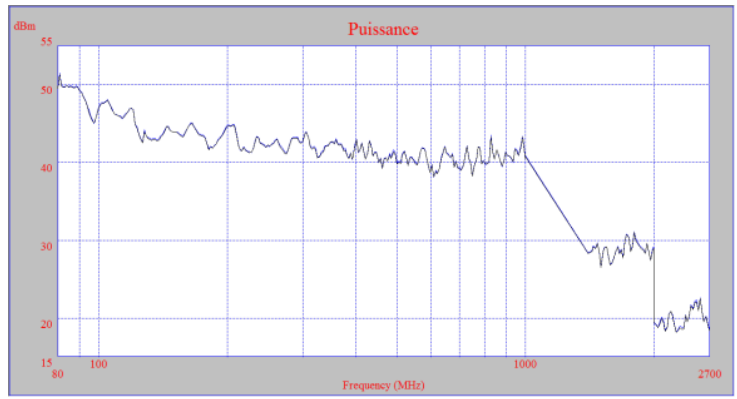

Fig 16.b: Power.

\section{Conclusion}

Many defects detection was observed between $80 \mathrm{MHz}$ and $2700 \mathrm{MHz}$ in both polarizations.

\subsection{Measurement Campaign in Real Situation (Outdoor)}

\subsubsection{Measurement Objectives}

The measures are designed to verify the reading displayed on the vehicle at different speeds passing to the reader, different configurations (positions and orientations) of the tag on the vehicle, different types of tags (only solution 2) tag and different configurations of the antenna. These results are summarized in tables of measures (see next sections).

\subsubsection{Test Environment and Material Resources}

The tests were conducted outside on the parking lot of the CISE ESIGELEC (see Figure 17) with a vehicle type Renault SPACE (athermal windscreen).
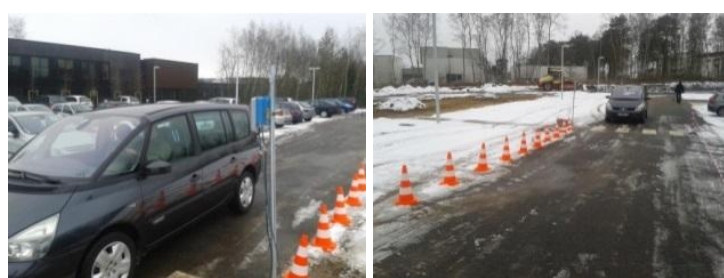

Fig 17: Test Environment for Outdoor Measurements on Solution 1 Materials.

\subsubsection{Solution 1: Measurement reading (outdoor)}

\subsubsection{Tests}

Several tests were carried out in Outdoor taking into account three main configurations: antenna, tag and reader. Two tests are presented to illustrate the process. The figures 18 and 19 show the antenna/tag configuration of the first test. The different results are presented in tables 3 and 4 .
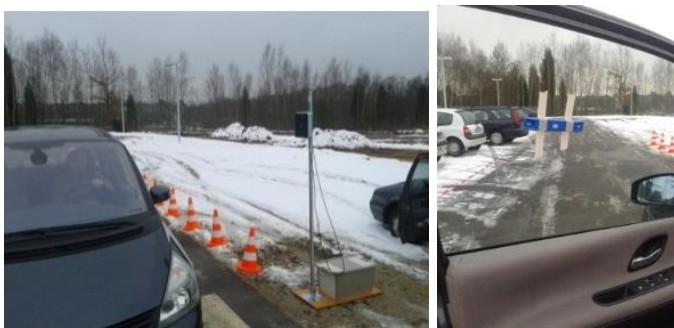

Fig 18: Test 1 Antenna/tag configuration. 
Table 3. Different results

\begin{tabular}{|l|l|l|l|l|}
\hline Materials & Configuration & $\begin{array}{l}\text { Vehicle } \\
\text { speed }\end{array}$ & $\begin{array}{l}\text { Reading } \\
\text { tag }\end{array}$ & Comments \\
\hline Antenna & $\begin{array}{l}\text { Taxiway } \\
\text { facing and } \\
170 \mathrm{~cm} \text { near } \\
\text { the floor } \\
\text { to } 35 \\
\mathrm{~km} / \mathrm{h}\end{array}$ & $\begin{array}{l}5 \mathrm{~km} / \mathrm{h}- \\
\text { OK }\end{array}$ & $\begin{array}{l}\text { Detection } \\
\text { in the } \\
\text { reader } \\
\text { axis }\end{array}$ \\
\cline { 1 - 2 } Tag & $\begin{array}{l}\text { Driver side } \\
\text { window and } \\
\text { horizontal } \\
\text { orientation }\end{array}$ & & & \\
\hline Reader & $\begin{array}{l}\text { Polling cycle } \\
300 \mathrm{~ms}\end{array}$ & & & \\
\hline
\end{tabular}

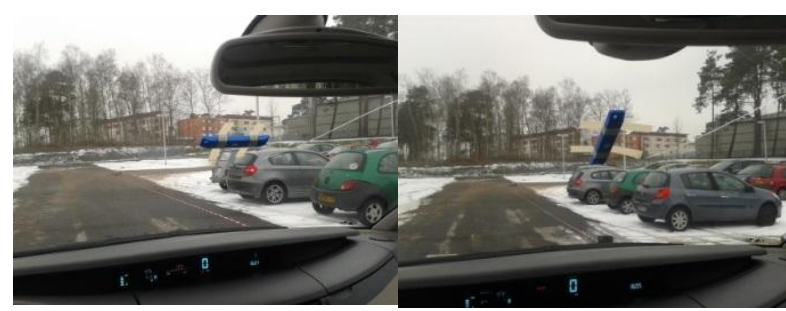

Fig 19: Test 2 Antenna/tag configuration.

Table 4. Different results

\begin{tabular}{|l|l|l|l|l|}
\hline Materials & Configuration & $\begin{array}{l}\text { Vehicle } \\
\text { speed }\end{array}$ & $\begin{array}{l}\text { Reading } \\
\text { tag }\end{array}$ & Comments \\
\hline Antenna & $\begin{array}{l}\text { Taxiway } \\
\text { facing and } \\
170 \mathrm{~cm} \text { near } \\
\text { the floor } \\
\text { to } 35 \\
\mathrm{~km} / \mathrm{h}\end{array}$ & $\begin{array}{l}5 \mathrm{~km} / \mathrm{h}- \\
\mathrm{KO}\end{array}$ & $\begin{array}{l}\text { Tag not } \\
\text { detected }\end{array}$ \\
\hline Tag & $\begin{array}{l}\text { Driver side } \\
\text { window and } \\
\text { horizontal } \\
\text { orientation }\end{array}$ & & & \\
\cline { 1 - 2 } Reader & $\begin{array}{l}\text { Polling cycle } \\
300 \mathrm{~ms}\end{array}$ & & & \\
\hline
\end{tabular}

\subsubsection{Synthesis}

The Figure 20 below summarizes the results of tests on Solution 1 materials. The results are shown by test family (family test is tests obtained for the same antenna orientation).

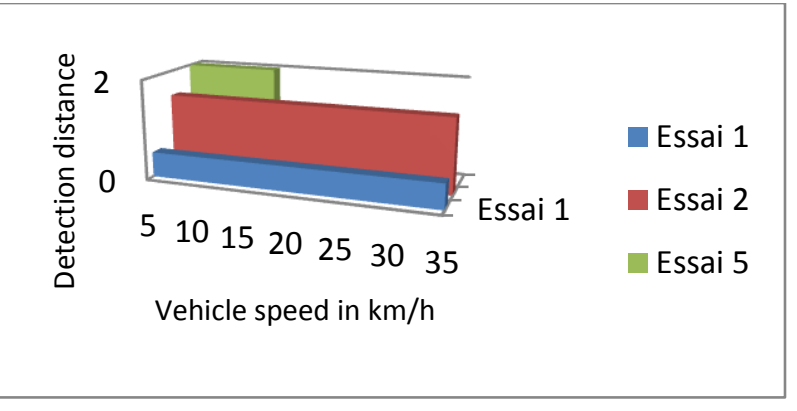

Figure 20.a: Synthesis of results of Tests 1 to 6 . Antenna facing the lane (only represented test data which have provided convincing results).

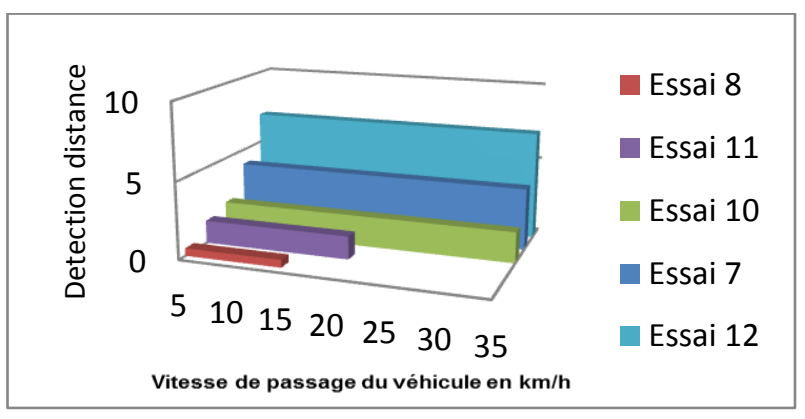

Figure 20.b: Synthesis of results 7 to 13. Antenna oriented at $45^{\circ}$ with respect to the traffic lane (only represented test data which have provided convincing results).

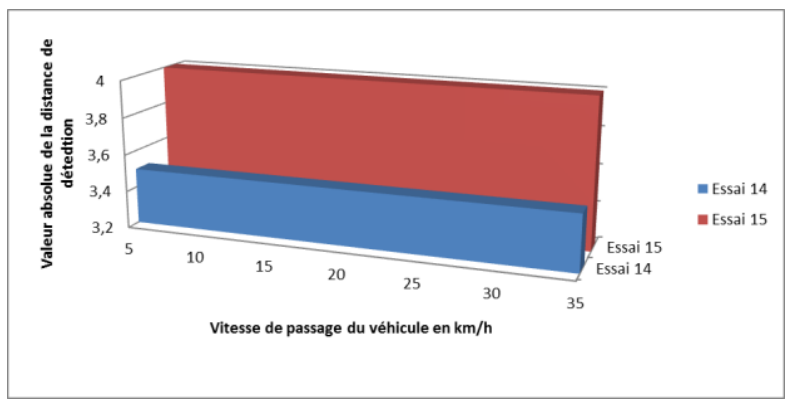

Fig 20.c: Synthesis of results 14 to 16. Antenna oriented at $45^{\circ}$ with respect to the traffic lane, at $0.70 \mathrm{~m}$ from the ground.

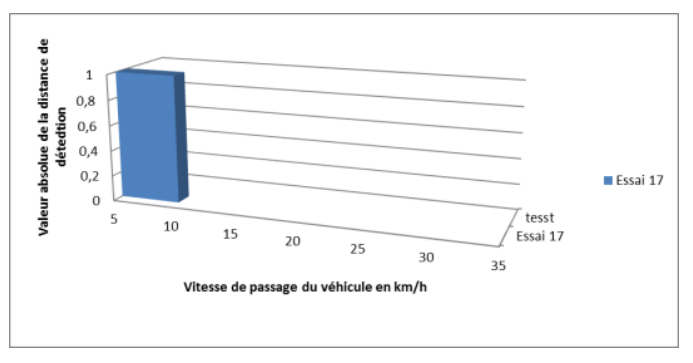

Fig 20.d: Synthesis of result 17. Antenna oriented at $70^{\circ}$ with respect to the circulation lane, at $0.70 \mathrm{~m}$ from the ground, tilted at $10^{\circ}$.

\subsubsection{Solution 2: Measurement reading}

3.2.4.1 Tests

As solution 1, several tests were carried out in Outdoor taking into account three main configurations: Antenna, Tag and Reader. Two tests are presented to illustrate the process. The 
figures 21 and 22 show the antenna/tag configuration of the first test. The different results are presented in tables 5 and 6 .

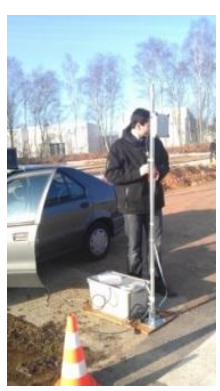

Fig 21: Test 1 Antenna/tag configuration.

Table 5. Different results

\begin{tabular}{|c|c|c|c|c|}
\hline Materials & Configuration & $\begin{array}{l}\text { Vehicle } \\
\text { speed }\end{array}$ & $\begin{array}{l}\text { Reading } \\
\text { tag }\end{array}$ & Comments \\
\hline Antenna & $\begin{array}{l}\text { Taxiway } \\
\text { facing and } \\
170 \mathrm{~cm} \text { near } \\
\text { the floor }\end{array}$ & \multirow[t]{3}{*}{$\begin{array}{l}5 \mathrm{~km} / \mathrm{h}- \\
\text { to } 35 \\
\mathrm{~km} / \mathrm{h}\end{array}$} & \multirow[t]{3}{*}{$\mathrm{OK}$} & \multirow[t]{3}{*}{$\begin{array}{l}\text { Tag } \\
\text { detected at } \\
1 \mathrm{~m} 50\end{array}$} \\
\hline Tag & $\begin{array}{l}\text { Driver side } \\
\text { window and } \\
\text { vertical } \\
\text { orientation }\end{array}$ & & & \\
\hline Reader & $\begin{array}{l}\text { Polling cycle } \\
5 \mathrm{~ms}\end{array}$ & & & \\
\hline
\end{tabular}

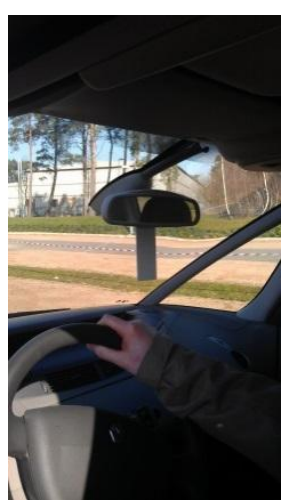

Fig 22: Test 2 Antenna/tag configuration.
Table 6. Different results

\begin{tabular}{|l|l|l|l|l|}
\hline Materials & Configuration & $\begin{array}{l}\text { Vehicle } \\
\text { speed }\end{array}$ & $\begin{array}{l}\text { Reading } \\
\text { tag }\end{array}$ & Comments \\
\hline Antenna & $\begin{array}{l}\text { Taxiway } \\
\text { facing and } \\
170 \mathrm{~cm} \text { near } \\
\text { the floor }\end{array}$ & $\begin{array}{l}5 \mathrm{~km} / \mathrm{h}- \\
\text { to } 35 \\
\mathrm{~km} / \mathrm{h}\end{array}$ & $\begin{array}{l}\mathrm{OK} \\
(5 \mathrm{~km} / \mathrm{h} \\
\text { to } 15 \\
\mathrm{~km} / \mathrm{h}) \\
\text { and } \mathrm{KO} \\
(\text { from } \\
20 \mathrm{~km} / \mathrm{h} \\
\text { to } 35\end{array}$ & $\begin{array}{l}\text { Tag } \\
\text { detected } \\
(5 \mathrm{~km} / \mathrm{h} \text { to } \\
15 \mathrm{~km} / \mathrm{h}) \\
\text { and not } \\
\text { detected } \\
(\text { from } 20 \\
\mathrm{km} / \mathrm{h} / \mathrm{h} \text { to } 35 \\
\mathrm{~km} / \mathrm{h})\end{array}$ \\
& $\begin{array}{l}\text { mirror fixed } \\
\text { tag and } \\
\text { vertical } \\
\text { orientation }\end{array}$ & & & \\
& $\begin{array}{l}\text { Polling cycle } \\
\text { Reader }\end{array}$ & & & \\
\hline
\end{tabular}

\subsubsection{Synthesis}

The Figures 23 summarizes the results of tests under the Solution 2. The results are shown by test family (family is a tests obtained for the same antenna orientation).

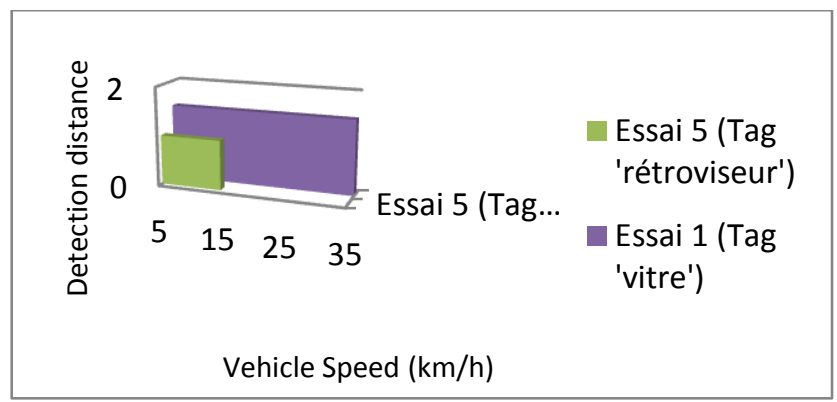

Fig 23.a: Synthesis of tests results from 1 to 6. Antenna facing the circulation lane, at $1.70 \mathrm{~m}$ from the ground

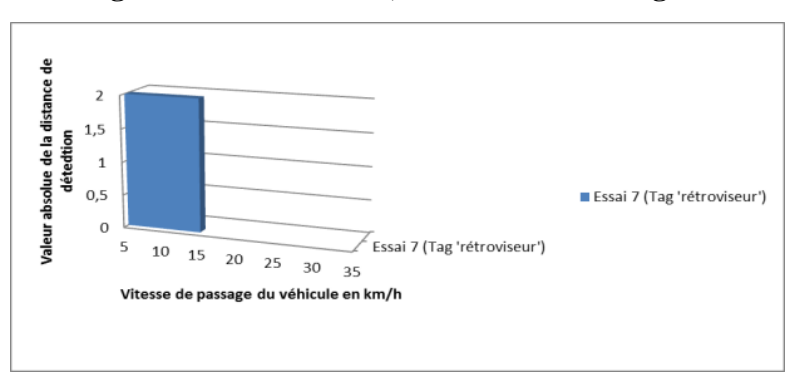

Fig 23.b: Synthesis of test 7 . Antenna oriented at $-\mathbf{4 5}^{\circ}$ with respect to circulation lane, at $1.70 \mathrm{~m}$ from the ground

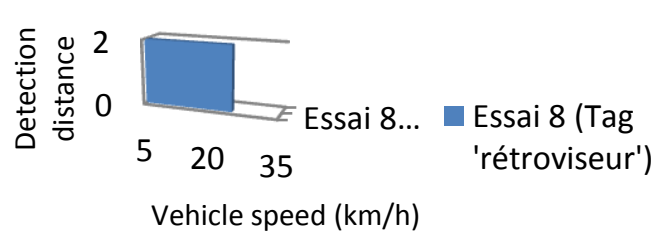

Fig 23.c: Synthesis of test 8 . Antenna oriented at $-30^{\circ}$ with respect of circulation lane, at $1.70 \mathrm{~m}$ from the ground. 


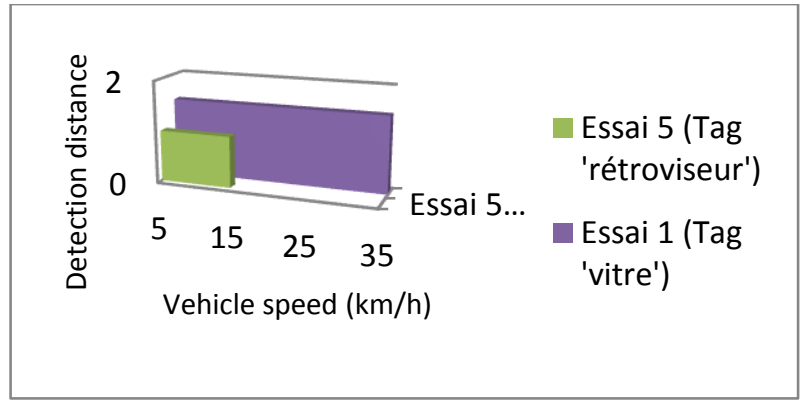

Fig 23.d: Synthesis of tests results 1 to 6. Antenna facing the circulation lane, at $1.70 \mathrm{~m}$ from the ground.

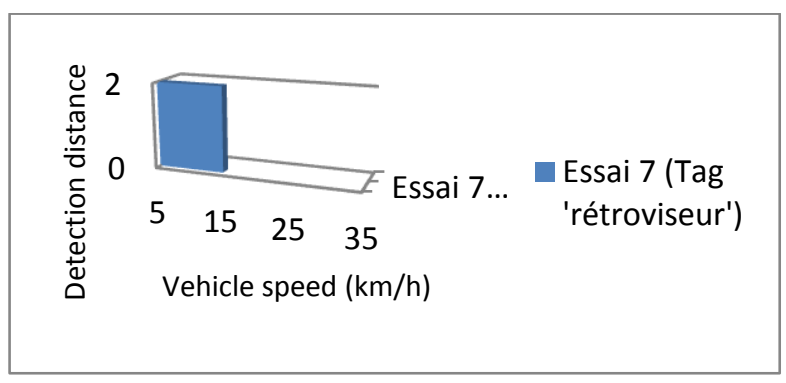

Fig 23.e: Synthesis of result test 7. Antenna oriented at $45^{\circ}$ with respect to circulation lane, at $1.70 \mathrm{~m}$ from the ground.

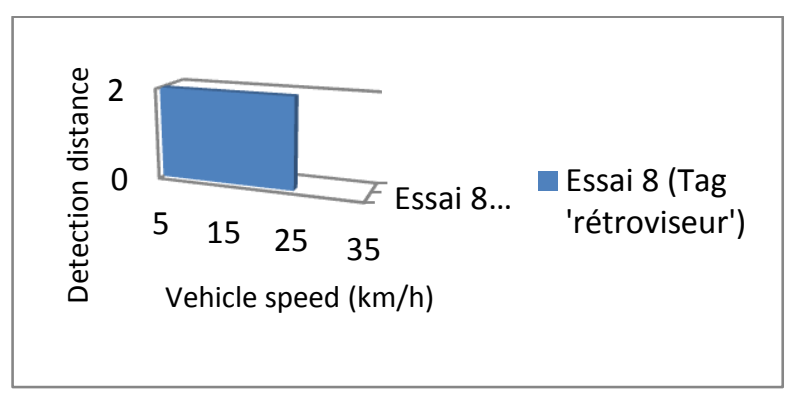

Fig 23.f: Synthesis of result test 8. Antenna oriented at $30^{\circ}$ with respect to the circulation lane, at $1.70 \mathrm{~m}$ from the ground.

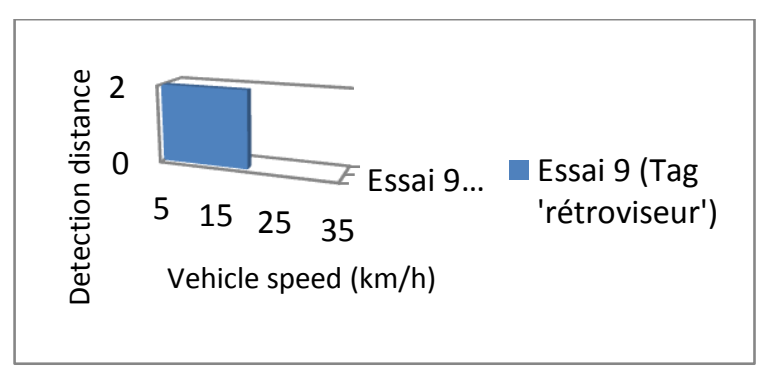

Fig 23.g: Synthesis of result test 8. Antenna oriented at $10^{\circ}$ with respect to the circulation lane, at $1.70 \mathrm{~m}$ from the ground.

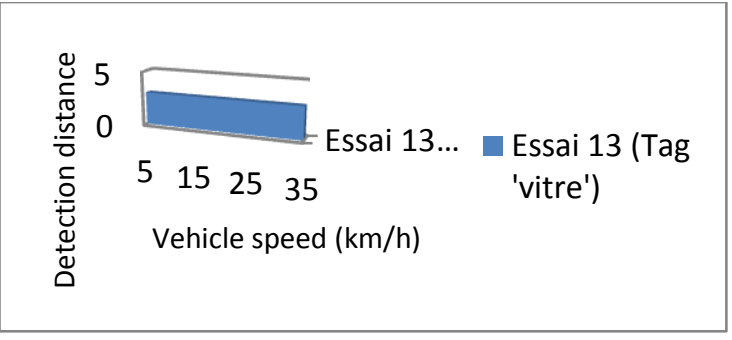

Fig 23.h: Synthesis of results tests 11 to 15. Antenna oriented at $45^{\circ}$ with respect of the circulation lane, at $1.70 \mathrm{~m}$ and $0.70 \mathrm{~m}$ from the ground.

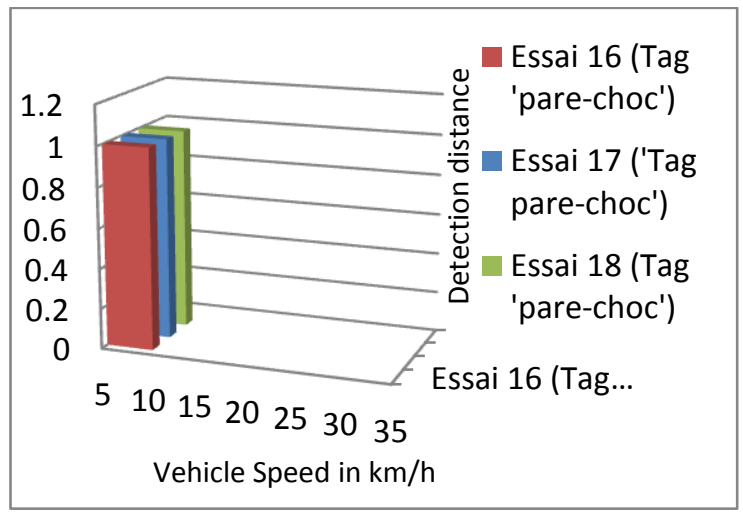

Fig 23.i: Synthesis of results tests 16 to 18 . Antenna oriented to $70^{\circ}$ with respect of the circulation lane, at $0.70 \mathrm{~m}$ from the ground, tilted at $10^{\circ}$.

\section{CONCLUSION}

This paper demonstrates the feasibility of deploying a solution based on RFID tracking for the issue of a RORO terminal port. Therefore, the solutions adopted and validated at the end of feasibility study, were tested and characterized in a controlled environment and outdoors environment. The table 7 contains different criteria for comparing both Solution 1 and 2 devices:

Table 7. Comparison between Solution 1 and 2

\begin{tabular}{|c|c|c|c|}
\hline Environment & Benchmarks & Sol 1 & Sol 2 \\
\hline \multirow{2}{*}{$\begin{array}{l}\text { Controlled } \\
\text { environment }\end{array}$} & Radiation pattern & A & $\mathrm{A}+$ \\
\hline & Radiated immunity & A & $\mathrm{C}$ \\
\hline \multirow{3}{*}{$\begin{array}{l}\text { Outdoor } \\
\text { environment }\end{array}$} & Device deployment & A+ & $\mathrm{A}+$ \\
\hline & $\begin{array}{l}\text { Reader/tag distance (tag } \\
\text { detection) }\end{array}$ & $A+$ & A \\
\hline & $\begin{array}{l}\text { Tag passage (tag } \\
\text { detection) }\end{array}$ & $\mathrm{A}+$ & $\mathrm{A}+$ \\
\hline
\end{tabular}

According the results presented in the table 7 , in vertical polarization, the radiation pattern of solution 1 appears more homogenous that solution 2 . In radiated immunity, some failures were observed for solution 2 . The establishment of the two devices is very simply. We note in the case of Solution 1 that the detection distance is larger than solution 2. In the last comparison test, we note that a maximum speed of vehicle 
passing (which limited to $35 \mathrm{~km} / \mathrm{h}$ given our configuration), both devices have provided the same detection.

Finally, in order to validate our solution, a half-day demonstration of the developed solution was performed in the presence of all partners and port stakeholders.

\section{ACKNOWLEDGMENTS}

The others present their thanks to the experts who have contributed towards development of the two solutions presented in this paper. They thank the IRSEEM Technological Resources Center (TRC) for giving at their disposal the tools and resources needed to develop traceability solution. A big thanks to partners who have provided the RFID hardware dedicated to traceability. Special thanks to the project leader "Grand Port Maritime du Havre".

\section{REFERENCES}

[1] O. Maurice, 2005. Introduction à la compatibilité électro Magnétique des systèmes embarqués et des télécommunications.

[2] G. Dun, 2007. Modélisation et optimisation de chambres anéchoïques pour applications CEM.

[3] D. Mullen. The application of RFID Technology in a port. AIM Global-Association for Automatic Identification and Mobility. pp. 181-182, Port Technology International. Warehousing and Logistics. PA 15086, USA.

[4] C. Bouvier, 2010. Projet de recherche et de développement collaboratif RORO MAX. CRITT T\&L. Internal report.

[5] F. Bourrieres, F. Kaiser, and F. Bourrieres, 2005. Procédé de traçabilité et d'authentification de containers et de produits sous scelle en circulation et/ou en transit. French Patent PCT/FR2005/002972, Nov. 11.
[6] N. Seriot, 2005. Les systèmes d'identification radio (RFID). Fonctionnement, applications et dangers. EIVD/HES-SO

[7] A. Ghiotto, M. Zurita, and S. Tedjini, 2005. Objet communicant avec lien RFID. INP Grenoble.

[8] S. Cavel and C. Millet, 2004. Les étiquettes RFID. EFPG INPG.

[9] P. Nikitin and K. V. S. Rao, 2006. Theory and measurement of backscattering from RFID tags. IEEE, Antennas and propagation, vol. 48, no. 6, pp. 212-218, Dec.

[10] C. Perrot, 2007. Mise en œuvre de la technologie RFID. in Networks Days, Strasbourg - France.

[11] D. Bechevet, 2005. Contribution au développement de tags RFID UHF et Microondes sur matériaux plastiques. INPG Thèse de Doctorat: optique et radiofréquence. 2005.

[12] K. Seong Leong, M. Leng Ng, and P. H. Cole, 2006 Operational considerations in simulation and deployment of RFID systems. 17th International Zurich Symposium on Electromagnetic Compatibility, Zurich. pp. 521-524.

[13] T.-Y. Eng, 2006. Mobile supply chain management: challenges for implementation. Technovation, vol. 26, pp. 682-686.

[14] H. Bauer, T. Reichardt, S. Barnes, and M. Neumann, 2005. Driving Consumer Acceptance of Mobile Marketing: A Theoretical Framework and Empirical. Journal of Electronic Commerce Research, vol. 6, no. 3.

[15] F. Bouzbouz, 2011. Geocolis Project. IRSEEM Rapport d'avancement. 